\title{
ON THE EFFECT OF WATER FLOW SPEED TO HYDRODYNAMIC RESISTANCE FORCE OF GILLNET; MODEL NET EXPERIMENTS IN THE FLUME TANK
}

\author{
Bambang Murdiyanto, Desty Maryam, and Hasan Basri
}

\author{
Lecturer in Faculty of Fisheries and Marine Science, Bogor Agricultural University, Bogor \\ Received February 1-2010; Received in revised form March 26-2010; Accepted April 6-2010
}

\begin{abstract}
When gillnet is operated in the sea its will encounter the effects of seawater current and tidal movements. The shape and construction of the gillnet will be effected by the direction and flow speed of the seawater current. When the current is strong enough the gillnet shape could be changing, falling down or even roll up. Eventually it will results on the net broken and the failure of fish catching. These net disorders could be caused due to the composition of the gillnet components was inappropriately fixed. The proper allotment of floats and sinkers could results fine gillnet endurance toward current since the buoyancy and sinking forces having significant role in maintaining the gillnet stability. This research is dealing with the experimental on the model net, float, and sinker in the flume tank to estimate the effects of flow speed toward hydrodynamic net resistance. The results of the laboratory experiments will be converted to calculate the optimum allotment of floats and sinkers fixed in the prototype of commercial gillnet.
\end{abstract}

KEYWORDS:

experiment, net model, flume tank, hydrodynamic force

\section{INTRODUCTION}

Monofilament gillnet and plied filament gillnet (jaring milenium) are fishing gears that commonly used by local fishers in Java Sea around northern Cirebon waters. These gears can be operated as fixed bottom gillnet for demersal fish and as a drift gillnet to catch pelagic fish. In practical used these gear could be changed its form and position due to hydrodynamic forces of seawater movement. The position and form of netting gear during fishing operation are greatly influenced by the hydrodynamic forces happen in the seawater.

The hydrodynamic forces acting to the gear are caused by seawater movement, reaction with fish or fish shoal movements, reaction between gear, and sea bottom, and the construction of the fishing gear itself (Fridman, 1986). Matsuda (1988) presumed that some factors which could effect the form and net stability in water were kinds of net material, design, and construction of netting gear, weight of the gear in water, wave, and seawater current velocity encountered the netting gear, the depth of the gear in the seawater, and the frictional forces between the netting gear and the sea bottom.

Stewart (1988) stated that the different of material kind and net size (e.g. mesh size, twine thickness and specific gravity) of the gear resulted in different net behavior in the seawater. Hard sea condition such as fast current of seawater speed could result in the dragging of gillnet or changing the gillnet form (roll over). Water flow speed up to $0.25 \mathrm{~m} / \mathrm{sec}$ could significantly change the vertical position of the gillnet (Stewart \& Ferro, 1985 According to Baranov (1973) \& Fridman (1973), gear design, net mesh size and hanging ratio of netting gear were some factors that influence netting gear resistance to hydrodynamic forces. In his theory of geometrical similarity Baranov (1973) stated that the changing of the net mesh size should result in the different size of fish catch. The modification of a fishing gear will not only technically change the gear performance but altering the gear fishing ability as well.

In this paper the author intends to estimate the proportionality of floats and sinkers in relation to the water flow speed for milenium gillnet, a prototype of gillnet used by local fishers operated as a bottom gillnet. This research was done by means of conducting model net experiment in a flume tank. Some measurements in this experiment were done partially to estimate the hydrodynamic resistance of gillnet components i.e. floats, sinkers and nets before converting to the prototype of milenium gillnet.

Theoretically the hydro dynamical forces acting on a gear could be estimated using the following formula (Fridman, 1986): 
$R=C \cdot q \cdot A$

where:

$\mathrm{C}=$ the hydrodynamic coefficient

$q=\tilde{n} . V^{2}$ is the hydrodynamic stagnation pressure $\left(\mathrm{kgf} . \mathrm{sec}^{2} / \mathrm{m}^{4}\right)=100$ for fresh water and $=105$ for sea water

$\tilde{n}=$ mass density of water $\left(\mathrm{kgf} / \mathrm{m}^{2}\right)$

$A=$ gear frontal area encountered the water flow $\left(\mathrm{m}^{2}\right)$

$V=$ the relative velocity of water flow to the gear $(\mathrm{m} / \mathrm{sec})$

$\mathrm{R}=(\mathrm{kgf})$

By calculating using this formula and measurements the external forces acting to the specimen used in the experiment the number of floats and sinkers toward certain water flow speed will be estimated for the prototype of a milenium gillnet.

\section{MATERIALS AND METHODS}

The net specimen consists of three kinds of netting material as described in Figure 1 and Table 1. Figure 2 shows float and sinker used in the experiments. Floats made from PVC material with cylindrical-oval form used in the experiment were similar with the kinds of floats commonly used by local fishers (Prado \& Dremiere, 1990). Floats consist of large and small sizes of $13.5-7.2 \mathrm{~cm}$ respectively. Sinkers were made from lead varied from 15, 35, and $75 \mathrm{~g}$ of its weight (Figure 2).
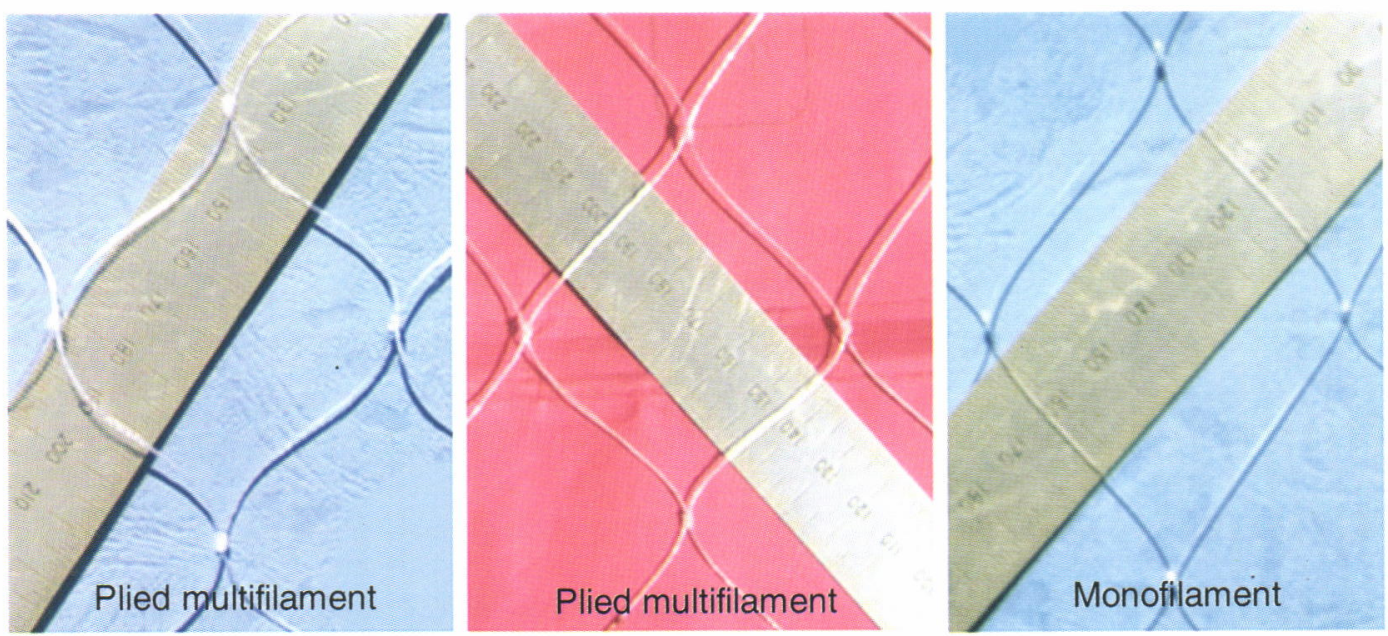

Figure 1. Kinds of net specimen (plied multifilament and monofilament).

Table 1. Kinds of netting material

\begin{tabular}{|c|c|c|c|c|c|}
\hline \multicolumn{4}{|c|}{ Milenium (plied monofilament) } & \multirow{2}{*}{\multicolumn{2}{|c|}{$\begin{array}{l}\text { Monofilament } \\
\text { (net I) }\end{array}$}} \\
\hline \multicolumn{2}{|c|}{ King white (net II) } & \multicolumn{2}{|c|}{ Natural white (net III) } & & \\
\hline $\begin{array}{l}\text { Twine thickness } \\
\text { (min) }\end{array}$ & $\begin{array}{l}\text { Mesh size } \\
(\mathrm{cm})\end{array}$ & $\begin{array}{l}\text { Twine thickness } \\
\text { (mm) }\end{array}$ & $\begin{array}{l}\text { Mesh size } \\
\text { (cm) }\end{array}$ & $\begin{array}{l}\text { Twine thickness } \\
\text { (mm) }\end{array}$ & $\begin{array}{l}\text { Mesh size } \\
\text { (cm) }\end{array}$ \\
\hline 10 & 10.0 & 1.0 & 10.4 & 0.4 & 10.0 \\
\hline
\end{tabular}

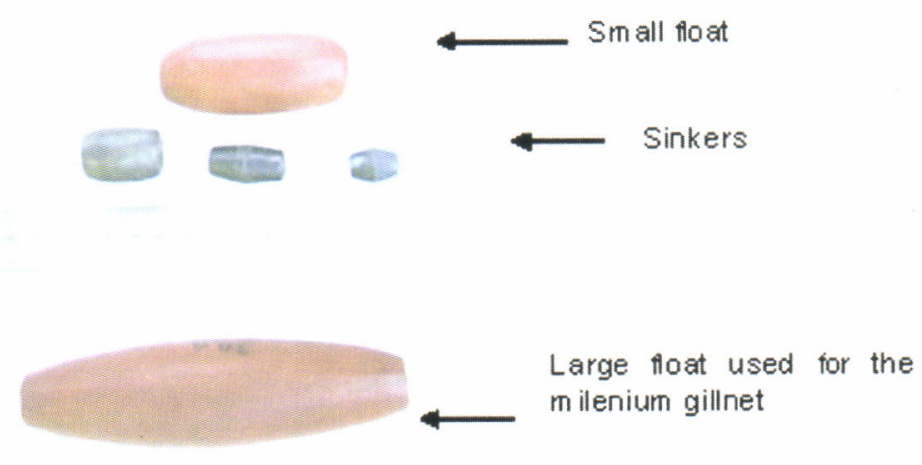

Figure 2. Floats and sinkers used for experiments. 


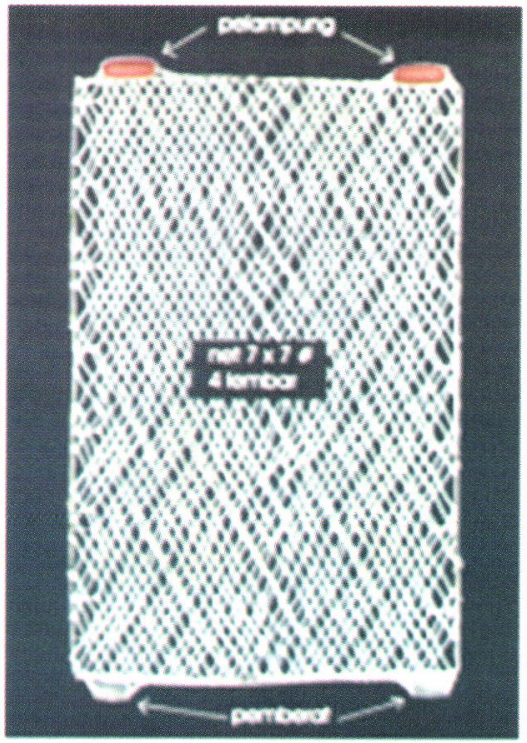

Figure 3.

Net panel specimen used for experiments.

The netting hydrodynamic resistance force is determined by means of measuring the resistance force of netting in the form of net panel in flume tank experiment. Each net panel consists of four pieces of net material mounted in a wire frame in a method without any overlapping of knots being occurred. Each net panel size for the three material kinds was 7 meshes long and 7 meshes wide (Figure 3), hang in a $30 \%$ hanging ratio.
Equipments used in the experiments were a flume tank belongs to the fishing laboratory of Faculty of Fisheries and Marine Science, Bogor Agricultural University used to measure the hydrodynamic resistance forces of net model components electrical and spring balances, water current flow speed meter, and digital camera (Figure 4).

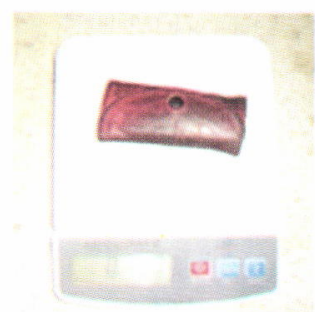

Electric balance

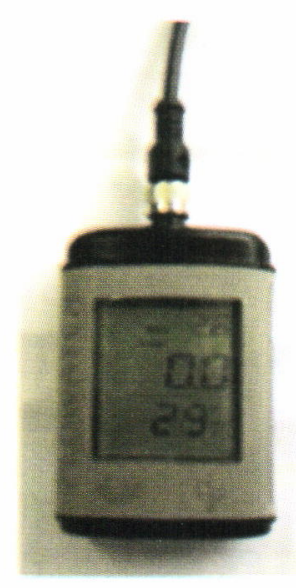

Figure 4.
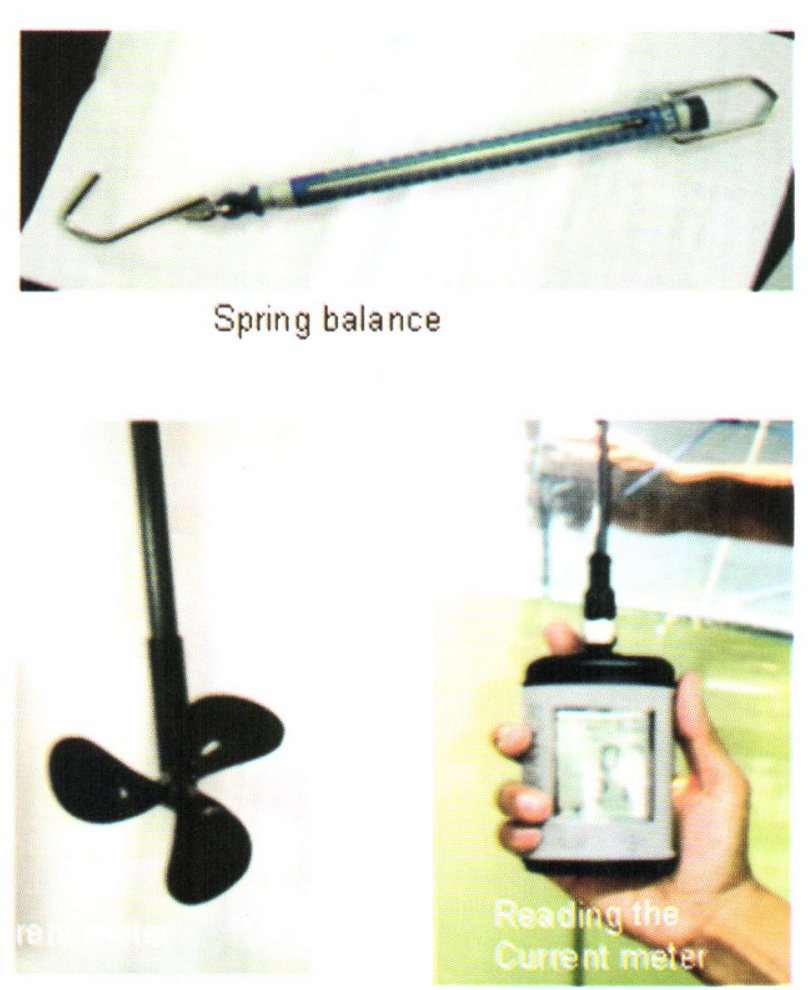

Some of apparatus used for experiment. 


\section{Methods}

Measurements of various water flow speed generated in the flume tank were done as a calibrating process to inspect the characteristics of flume tank as testing equipments. Floats and sinkers

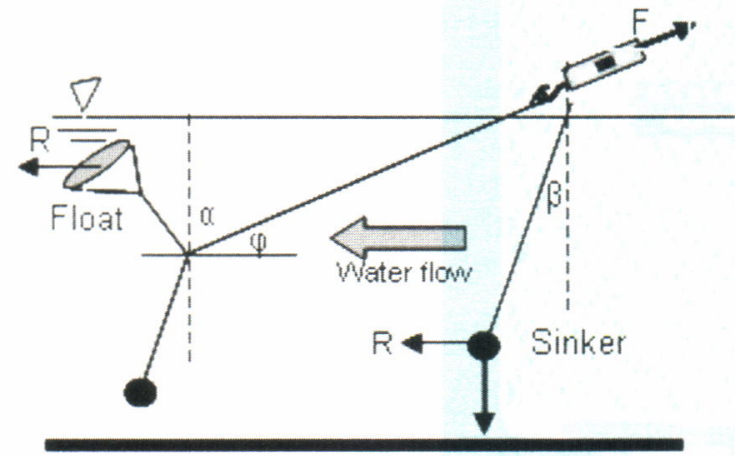

Flume tank bottom hydrodynamic resistance against water flow speed were done directly by soaking the tested objects and then running the flume tank. The magnitude of dragging forces was measured with spring balance as described in Figure 5.

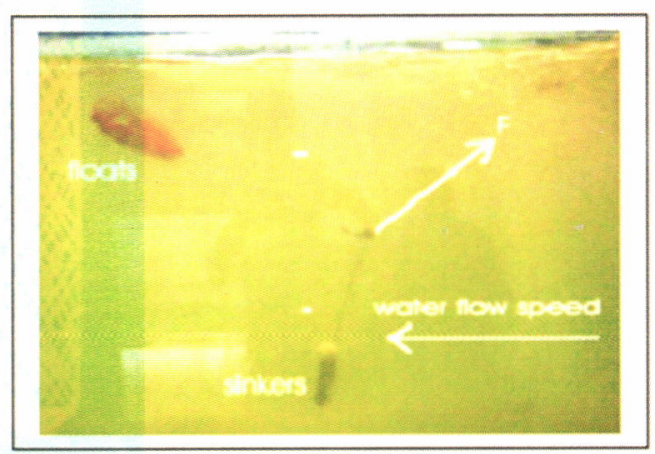

Figure 5. Illustration of the floats and sinkers hydrodynamic resistance forces measuring methods.

Figure 6 is showing the procedure of experiments to measures the hydrodynamic resistance forces of the net panels. Net panel was fixed with twine to stopper and to spring balance so the external force generated by water flow, which encountered the net panel, could be measured.

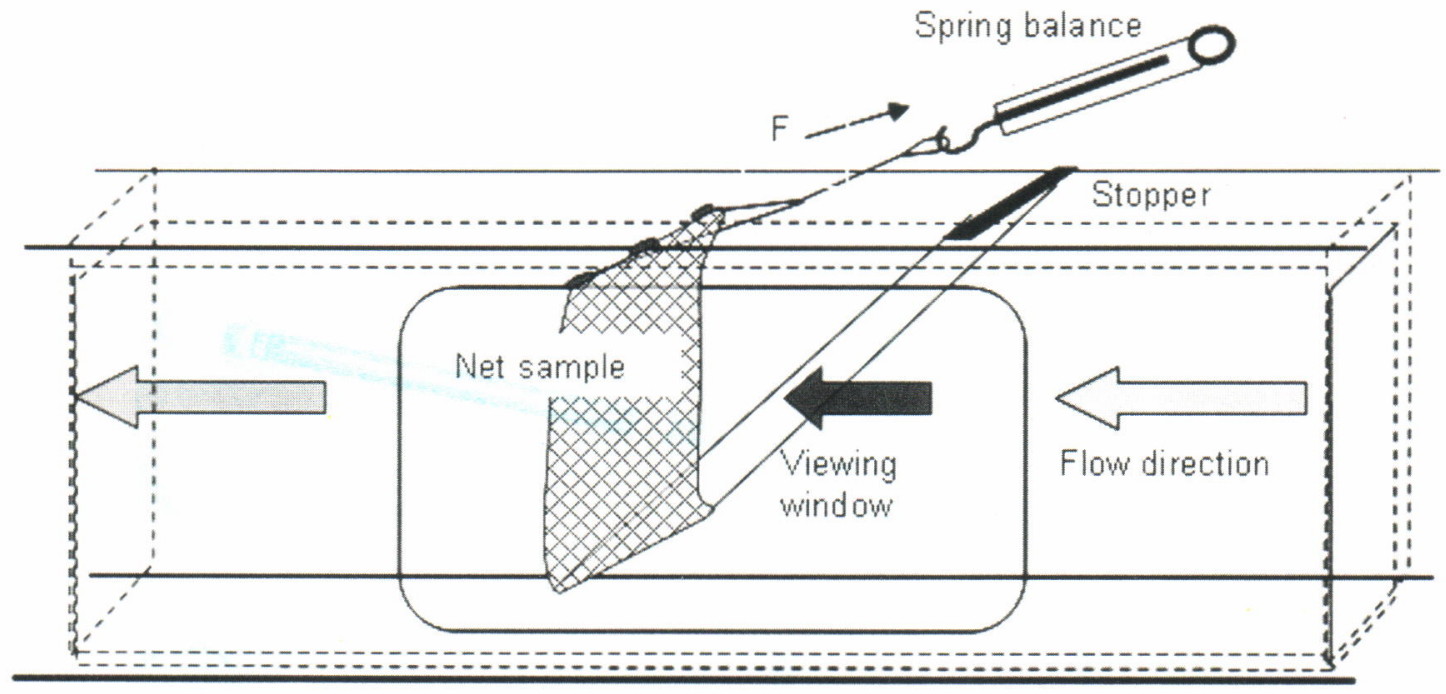

Figure 6.

Diagram illustration on the net panel measuring procedure in the flume tank experiment.
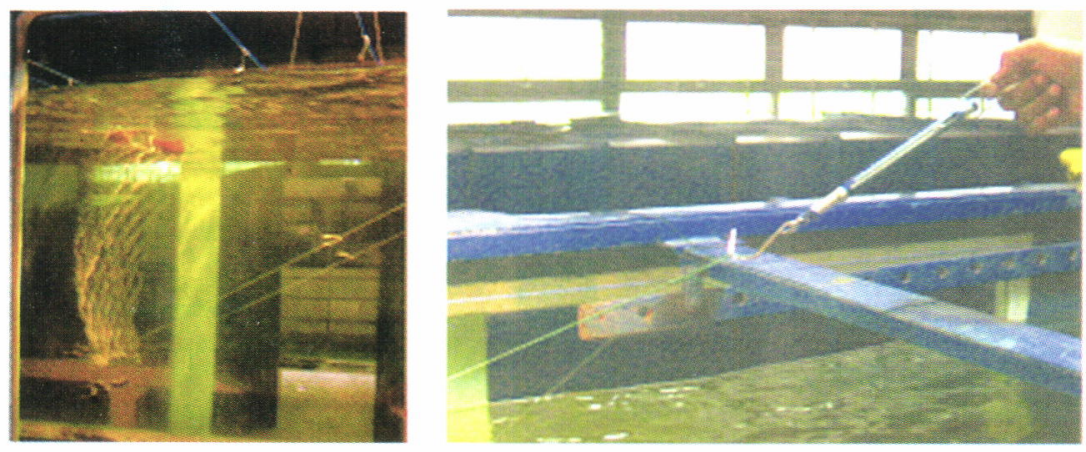

Figure 7.

Pictures of measuring procedure in the flume tank experiment. 


\section{RESULTS AND DISCUSSION}

The calibration of Faculty of Fisheries and Marine Science, Bogor Agricultural University flume tank resulted that this equipment in its operation produces a periodically water flow speed changes Figure 7 . This equipment can generate up to $0.7 \mathrm{~m} / \mathrm{sec}$ even though the flow speed cannot be keep constant. It is recommended not to run the flume tank in faster speed condition. The water flow speed that can be generated varies from ca. $0.10-0.7 \mathrm{~m} / \mathrm{sec}$. During operation the water in the tank streaming with a certain cadence from weak to strong flow. Figure 8 and 9 explain the relation between water flow speed and the hydrodynamic forces acting to the large $(13.5 \mathrm{~cm}$ long) and small $(7.2 \mathrm{~cm}$ long) float respectively. The hydrodynamic drag forces acting to the large float varies from $2.8-60.3 \mathrm{~g}$. The hydrodynamic drag forces toward small floats vary from $2.4-51.5 \mathrm{~g}$.

Figure 10 is showing the relation between water flow speed and the hydrodynamic forces acting to the sinkers. The drag force acting to sinker is up to $10 \mathrm{~g}$.

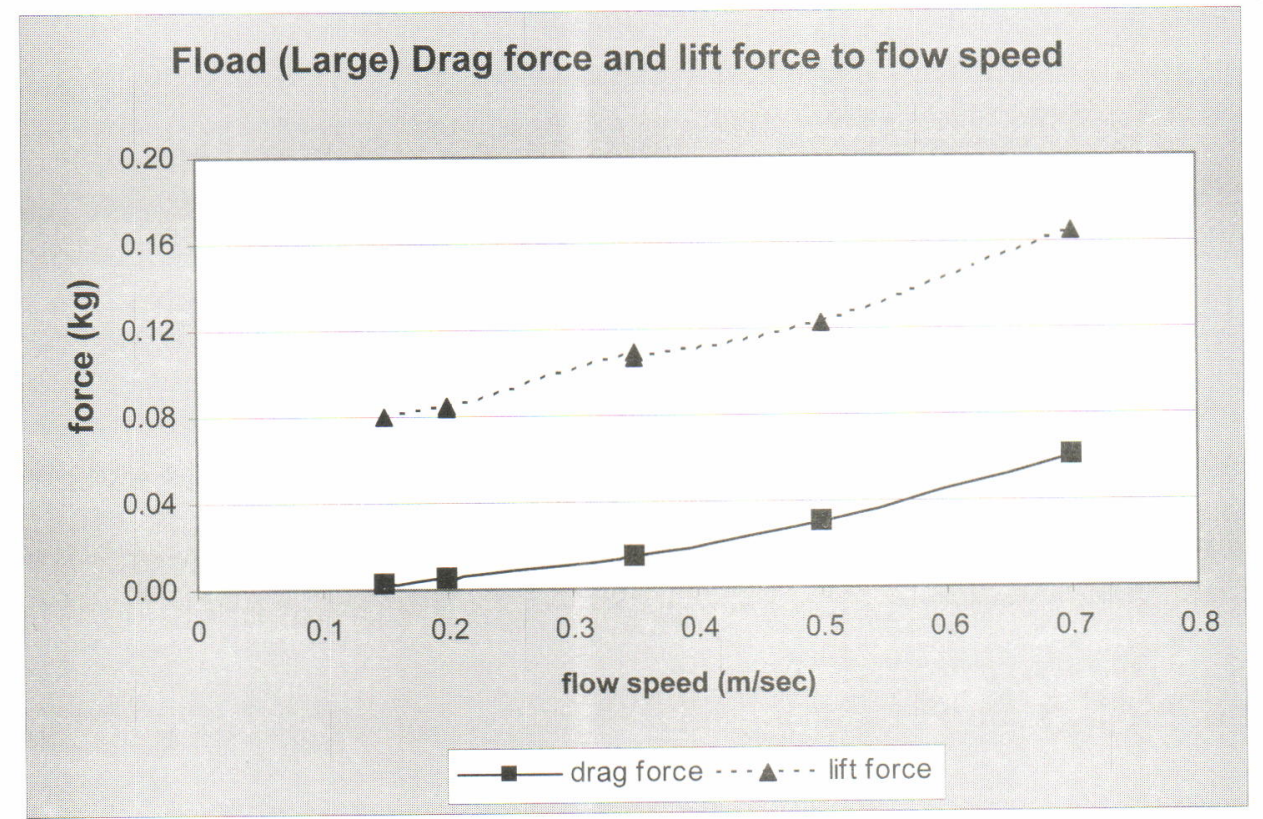

Figure 8. The relation between water flow speed and the hydrodynamic forces acting to the large float.

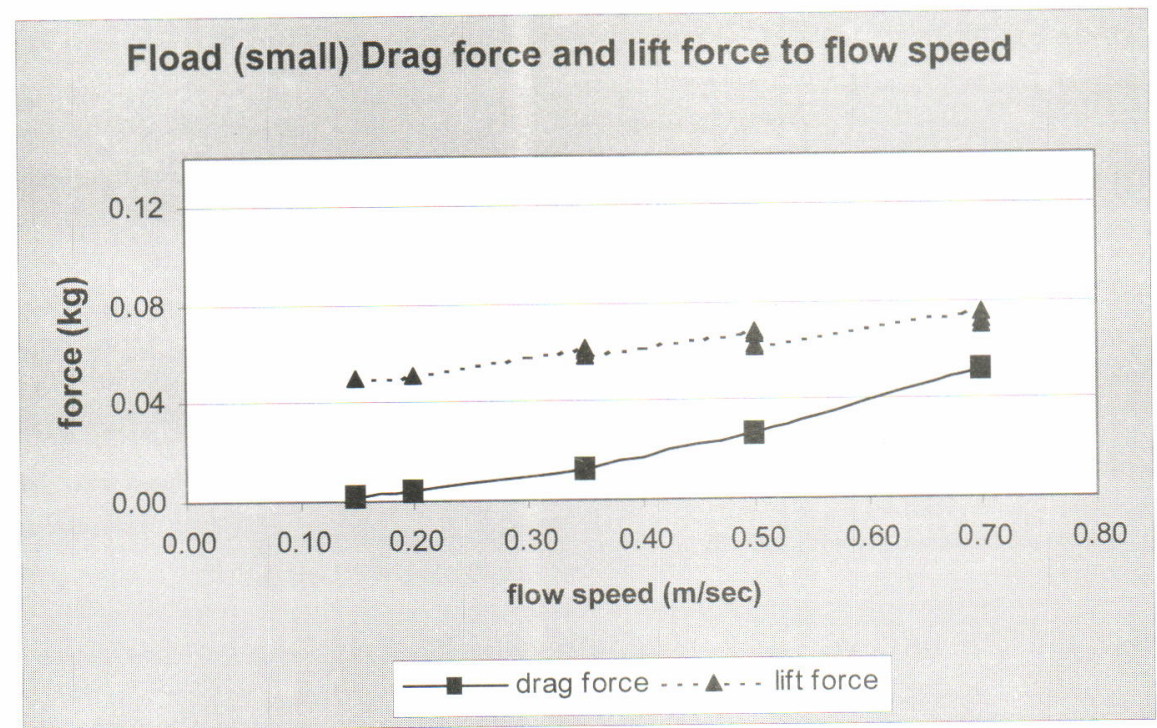

Figure 9. The relation between water flow speed and the hydrodynamic forces acting to the small float. 


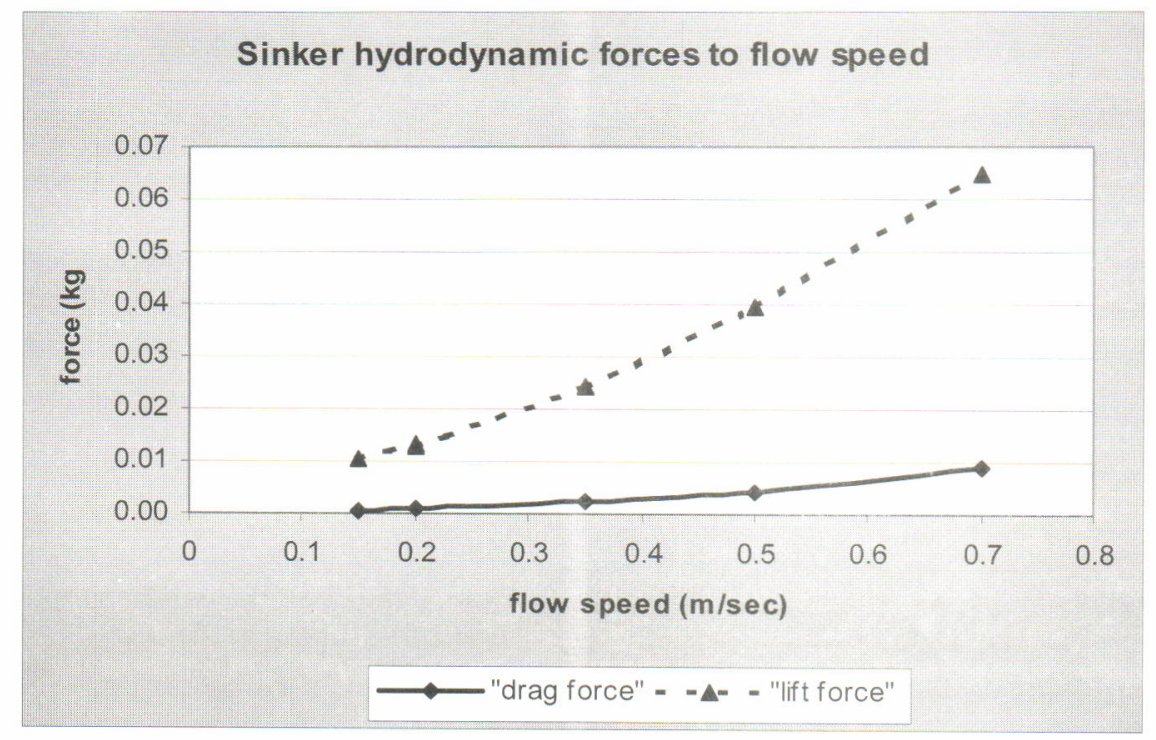

Figure 10. The relation between water flow speed and the hydrodynamic forces acting to the sinker.

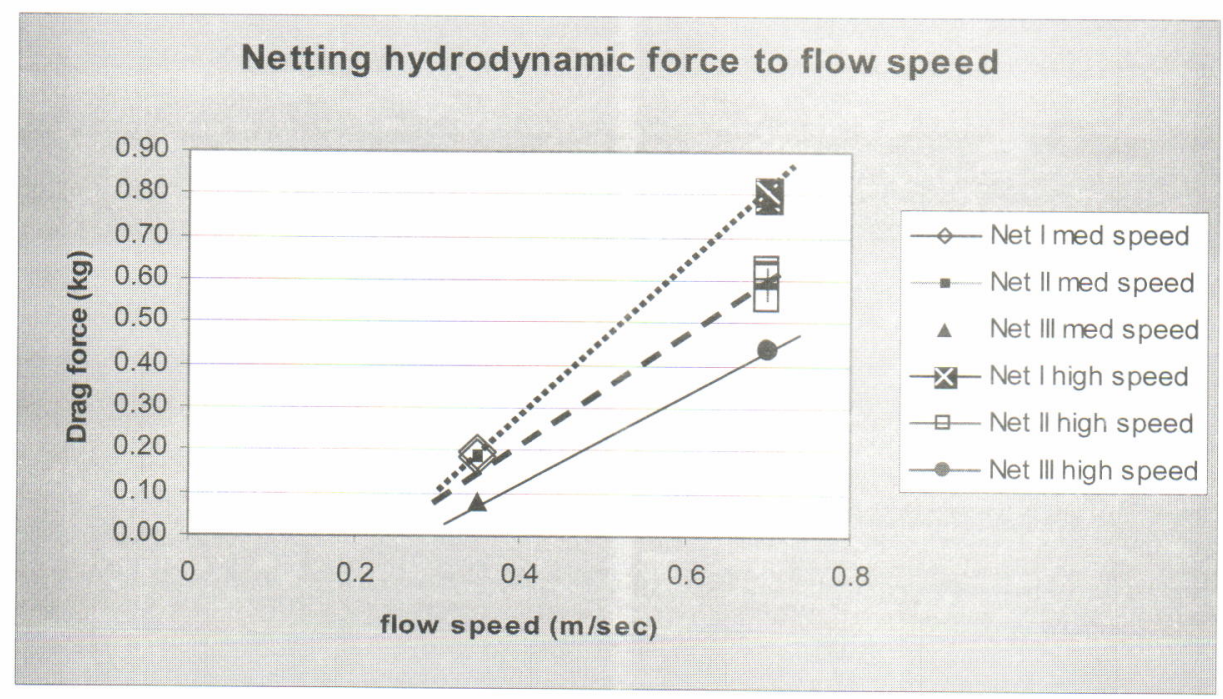

Figure 11. The relation between the flow speed and hydrodynamic drag forces acting to the net panel.

The experiment results of net panel measurements can be seen in Figure 11. The results show that for the water flow speed of $0.15-0.7 \mathrm{~m} / \mathrm{sec}$ give ca. (circa: more or less $0.2-0.8 \mathrm{~kg}$ hydrodynamic drag forces to the plied monofilameı ıt net panels and ca. 0.2-0.4 kg to the monofilament net panels.

Table 2.

Calculation of the gillnet monofilament component

\begin{tabular}{|c|c|c|c|c|c|c|c|c|}
\hline Items & Number & $\begin{array}{c}M \\
(\#)\end{array}$ & $\begin{array}{c}\mathbf{N} \\
(\#)\end{array}$ & $\begin{array}{l}W \\
(\mathrm{~kg})\end{array}$ & $\begin{array}{l}W_{W} \\
(\mathrm{~kg})\end{array}$ & Buoyancy & $\begin{array}{l}\text { Drag force }(\mathrm{kg}) \\
\text { or } \\
\text { sinker resistant }\end{array}$ & $\begin{array}{l}\text { Resistance } \\
\text { force with } \\
\text { ground effect. }\end{array}$ \\
\hline Net & & 1,600 & 100 & 6 & 0.72 & & 3.59 & \\
\hline Float (large) & 100 & & & 0.86 & & 7 & 7.8 & \\
\hline Sinker & 300 & & & 21.6 & 19.5 & & 2.64 & 10.34 \\
\hline Total & & & & & 20.22 & & 14.05 & \\
\hline Sinker & 410 & & & 29.52 & 26.65 & & & 14.12 \\
\hline
\end{tabular}

Additional sinkers numbers for maximum flow speed $0.7 \mathrm{~m} / \mathrm{sec} .=110$ floats

Remarks: M: mesh number in horizontal direction; N: mesh number in vertical direction; W: dry weight of net component in $\mathrm{kg}$; WW: wet weight of net component in $\mathrm{kg}$ 
Table 3. Calculation of the plied monofilament gillnet (gillnet milenium)

\begin{tabular}{|c|c|c|c|c|c|c|c|c|}
\hline Items & Number & $\begin{array}{c}\text { M } \\
(\#)\end{array}$ & $\begin{array}{c}\mathbf{N} \\
(\#)\end{array}$ & $\begin{array}{c}\text { W } \\
(\mathbf{k g})\end{array}$ & $\begin{array}{l}W_{w} \\
(\mathrm{~kg})\end{array}$ & Buoyancy & $\begin{array}{l}\text { Drag force }(\mathbf{k g}) \\
\quad \text { or } \\
\text { sinker resistant }\end{array}$ & $\begin{array}{c}\text { Resistance force } \\
\text { with ground } \\
\text { effect. }\end{array}$ \\
\hline Net & & 1,600 & 100 & 16 & 1.92 & & 6.53 & \\
\hline Float (large) & 100 & & & 0.862 & & 7 & 7.82 & \\
\hline Sinker & 300 & & & 21.6 & 19.5 & & 2.64 & 10.34 \\
\hline Total & & & & & 21.42 & & 16.99 & \\
\hline Sinker & 495 & & & 35.64 & 32.18 & & & 17.05 \\
\hline
\end{tabular}

Table 2 and 3 represent the conversion results from the measurement of net model in the flume tank with the prototype bottom gillnet used by local fishers made from plied monofilament (locally called milenium) and using monofilament material. Monofilament gillnets with $90 \mathrm{~m}$ length (1,600 \# meshes) and depth of 100 \# meshes usually furnished with some 100 numbers of floats and 300 numbers of sinkers. Same items for plied monofilament (milenium) bottom gillnet, either natural white, or king white material as well.

When the condition of the current flow speed increases, then in order to keep the gillnet stability the composition of proportional number of floats and sinkers should be changed. By estimating that the sea bottom condition consists of mud and sand, the ground effect coefficient of 0.53 (for lead sinker) was used to calculate the drag forces. If the current speed increase up to $0.7 \mathrm{~m} / \mathrm{sec}$ then some 410 numbers of sinker were needed (ca. $29.52 \mathrm{~kg}$ of total weight) or in other words some 110 numbers of sinker (ca. 7.92 $\mathrm{kg}$ of total weight) should be added to the monofilament bottom gillnet. As for the plied monofilament (milenium) bottom gillnet in the same case then some 495 numbers of sinker were needed (ca. $35.64 \mathrm{~kg}$ of total weight) or some 195 numbers of sinker (ca. $14.04 \mathrm{~kg}$ of total weight) should be added to the gillnet.

The measurements to the net panels indicated that net panel made from monofilament material gives smaller resistance force than the net panel made from plied monofilament.

Since the experiment carried out using fresh water (mass density $=100 \mathrm{kgf}-\mathrm{sec}^{2} / \mathrm{m}^{4}$ ) while the prototype gillnet that used to be operated in seawater (mass density $=105 \mathrm{kgf}-\mathrm{sec}^{2} / \mathrm{m}^{4}$ ) in the converting might be result in a slight difference. But in the calculation of resistance forces results only a very slight minor differences so that can be neglected.

\section{CONCLUSIONS}

1. The Faculty of Fisheries and Marine Science, Bogor Agricultural University flume tank is practically viable to be used for experiments. The flume tank can generate water flow speed up to $0.7 \mathrm{~m} / \mathrm{sec}$. It is recommended not to operate the flume tank exceeding this limit of water flow velocity, since it might harm this equipment.

2. The hydrodynamic forces acting in the experiment objects i.e. floats, sinkers and net panels positively change as the flow speed going faster.

3. The results of converting calculation from laboratory experiments to the prototype of bottom gillnet recommend that some additional sinkers need to be attached to a piece of bottom gillnet when current speed change up to $0.7 \mathrm{~m} / \mathrm{sec}$ in order to keep the gillnet stable. For a piece of bottom gillnet made from monofilament with 100 meshes wide and 1,600 meshes long with $60 \%$ hanging ratio need some 410 lead sinkers (ca. $29.52 \mathrm{~kg}$ of total weight). For similar gillnet made from plied monofilament material (milenium) need additional of some some 495 numbers of sinker (ca. 35.64 $\mathrm{kg}$ of total weight) were needed.

\section{ACKNOWLEDGEMENTS}

The author wish to express his thanks to PT. Indoneptune Net Manufacturing Company, in Bandung city, Indonesia, fc: providing the netting specimen to be used in experiments.

\section{REFERENCES}

Baranov, F. I. 1973. Commercial fishing techniques. Chap.8. Theory of Gillnets Fishing. Pishchevaya Promyshlennost, Moscow. (Translated from Russian By the Ontario Department of Lands and Forests. Maplc. Ont. 1,631 pp.

Fridman, A. L. 1973. Theory and Design of Commercial Fishing Gear. Israel Program for Scientific Translations. Jerusalem. 489 pp.

Fridman, A. L. 1986. Calculation for Fishing Gear Design. Food and Agriculture Organization. Rome. 
Matsuda, K. 1988. Headline height of bottom gillnets set across a water flow. Fish. Res. 6: 167-179.

Prado, J. \& Dremiere. 1990. Fisherman's Workbook. Food and Agricultural Organization of the United Nations. Fishing News Books. Oxford. 180 pp.
Stewart, P. A. M. 1988. Measurements of the effect of tidal flow on the headline heights of bottom set gillnets. Fish. Res. 6: 181-189.

Stewart, P. A. M. \& R. S. T Ferro. 1985. Measurements on gillnet in a flume tank. Fish. Res. 3: 29-46. 